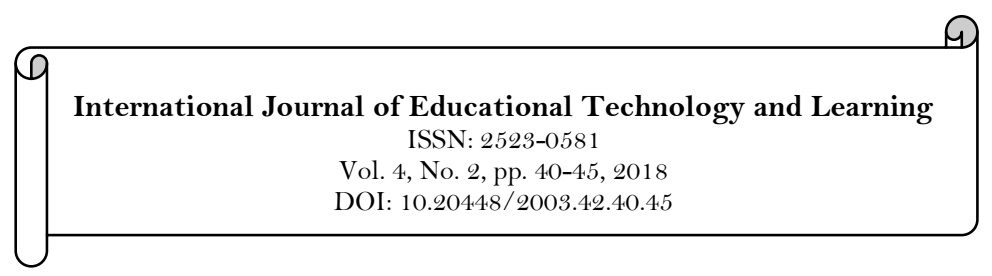

Cupdates

\title{
The Benefits of Using Facebook Live for Listening Activities in A Korean University EFL Classroom
}

\author{
Chris Kobylinski ${ }^{1}$ \\ ${ }^{1}$ Communicative English at Hanguk University of Foreign Studies in Seoul, South Korea. \\ Email:chriskobv@hufs.ac.kr
}

\begin{abstract}
Although the methods and mediums of receiving information have rapidly changed, the main method of presenting listening activities in an English as a Foreign Language (EFL) classroom has not. More and more people are using social networking services (SNSs) as their source for daily information, yet most EFL classrooms still use voice only recordings for listening activities. To keep up with the changes and to provide students with real authentic listening experiences, many teachers have begun to use SNSs in their classrooms. This paper examines the strengths and weaknesses of using Facebook Live as an authentic source for listening activities in an EFL classroom. The data collected revealed a variety of strengths and weaknesses of this application, and showed potential for use within the classroom and for allowing students to practice listening outside the classroom.
\end{abstract}

\author{
Keywords: \\ EFL \\ ELT \\ Facebook live \\ Listening \\ Listening activities \\ SNS. \\ Licensed: \\ This work is licensed under a \\ Creative Commons Attribution \\ 4.0 License. \\ Publisher: \\ Scientific Publishing Institute
}

\section{Introduction}

In the past decade or so, SNS has become an influential part of our daily life. A social networking service (SNS) is an online platform that is used by people to build social networks or social relations with other people who share similar personal or career interests, activities, backgrounds or real-life connections (Wikipedia 2018). Many people use SNS for a variety of purposes and some teachers have been using SNS in the classroom. Out of all the SNS platforms, Facebook still remains the most popular. Over 2.2 billion people actively use Facebook and 1.45 billion people use Facebook on a daily basis (Facebook 2018). While many users use Facebook for personal communication, many also use it as a source of news and information. Facebook is an SNS that is widely used both in and outside the classroom by people all over the world. In the classroom, many teachers use Facebook as a way to communicate with students and parents and to share information. Teachers can create their own public figure page that can be viewed by everyone or they can create a private group for their own students.

On April 6th, 2016, Facebook launched Facebook Live as a way to share live videos (Facebook). This study examines using Facebook Live in and outside the classroom to give EFL (English as Foreign Language students) an opportunity to listen to and interact with people all over the world. The aim of this project was not only to see if Facebook Live could be used in the classroom, but also to help the students to view Facebook Live as a resource that could be used outside of the classroom. Pegrum (2000) stated:

"The bridges built between the classroom and the outside world, and the more gradual transition to

"post-classroom experience", will not only make language study more meaningful and motivating, but will stand the students in good stead when it comes time for them to go forth as completely independent learners, without the support of teachers, classmates or a language classroom

(“Conclusion," para. 1)."

As SNS becomes more popular, it should be the aim of the EFL teacher to not only bring it into the classroom, but to also show their students how to properly use it themselves outside of the classroom. This paper will examine the pros and cons of using SNS in the classroom, because there is very little research about using Facebook Live in the classroom, especially for listening activities. The study will then attempt to see if Facebook Live also has similar pros and cons and to outline a course of action to use Facebook Live in the EFL classroom. 


\section{Literature Review \\ 2.1. Pros}

The popularity of Facebook and of live streaming videos among university students is well known, but can the streaming videos of Facebook Live offer any educational benefits? When compared to traditional voice only recordings, the use of video offers some advantages. Over 30 years ago, Ur (1984) addressed this benefit of video compared to traditional voice-only recordings; "If the speaker is usually present in real life listening situations, towards which we wish to train our students in the classroom, then perhaps we should think again about how much we ought to use live recordings as the basis of our exercises (p. 5).” Additionally, as SNS becomes the preferred form of communication, it is important that SNS becomes the basis of exercises.

Videos have been used effectively in EFL classrooms, yet SNS and more specifically Facebook Live videos offer added benefits to prerecorded videos. Lederer (2012) stated, "as an educational tool, social media enriches the learning experience by allowing students and teachers to connect and interact in new, exciting ways (p. 2).” Facebook Live allows students to connect and interact in new ways by allowing both real time experiences and the ability to go back and replay the videos to obtain additional information. Students can watch the videos live and interact via messages or just focus on listening. This creates a very authentic listening experience. However, if the student misses something, they do have the ability to replay the video later on to recheck their comprehension. This feature allows Facebook Live to offer the benefits of traditional video, the ability to watch again, and the benefit of live streaming video - the real-time interaction and authenticity.

This real-time interaction and authenticity is a benefit that traditional videos and voice-only recording do not offer and leads to another potential benefit of using Facebook Live in the classroom. Inayati (2013) highlighted interactivity as one the positive features of using social media in ELT. Facebook Live offers and interactive element that isn't found in most traditional listening activities. Barseghian (2011) posted a list on why Facebook should be used in the classroom and one reason applies specifically to Facebook Live: "students can listen more actively: Students may passively listen to lectures, but interactively using Facebook will result in active learning." The interactive nature of Facebook Live creates a classroom environment that results in active listening. Students must also analyze and think about the content if they wish to engage with the speaker. This is a benefit that is unique to a live video.

Facebook Live also allows teachers to introduce a variety of English speakers to the classroom. While many EFL teachers want to introduce the diversity of the English language to the classroom, many ELT (English Language Teaching) resources lack diversity. Galloway and Rose (2017) found it troublesome that many of ELT materials available to teachers failed to show the diversity of English that exists. This lack of diversity is particular evident in many of the text books and listening activities that are used by most teachers. However, Facebook Live enables teachers to supplement these materials with richer and more diverse listening opportunities. In today's modern and global environment, Facebook Live allows students to start experiencing these global exchanges in and outside the classroom and can prepare them for how to appreciate the diversity of English and deal and cultural differences.

Using Facebook Live has another benefit; it allows teachers a chance to help students to use it outside of the classroom. Prensky (2005) argued that technology's sole role should be to support students teaching themselves. Facebook Live offers teachers the chance to show their students how to listen to and to respond to videos in class, and to then use the resources outside of class on their own. Wu (2016) contends that Facebook, as a learning tool, can be integrated in to the students' daily life and allow students to access resources that meet their needs. If students learn to view Facebook Live as a learning tool inside the classroom, they might be more likely to use it outside the classroom. Many teachers in EFL classrooms are faced with a shortage of time and Facebook Live gives students a chance to engage with people and content that interests them outside the classroom. Teachers can use Facebook Live for in-class listening, but also show students how to use it effectively on their own as well.

Exposure to and practice with authentic texts through Facebook Live can help to prepare students for both the modern workplace and the global world that they will face after they leave school. Greenberg and Zanetis (2012) stated that "students in colleges and universities expect video training as practical workforce preparation (p. 21)." As more and more individuals and companies use Facebook Live to communicate with people and customers, familiarity with this resource and competency in using it can become a transferable skill used in many fields. Additionally, Greenberg and Zanetis (2012) also touch on how live video can help improve global communication.

"Video (accompanied by proper instruction) can also help students of all ages prepare for a future as global citizens because it allows them to meet students and teachers around the world, experience their culture, language, and customs while gaining a deeper understanding and respect for different values and ideas (p. 22)."

Overall, Facebook Live is a unique tool in the EFL teacher's toolbox because it is readily available, free, and it combines the best aspects of traditional videos and of the modern interactive aspects of live streaming video. In addition, Facebook Live can be used by readily used by many students outside of the classroom, as a powerful supplement to their language development and a key tool in improving their communicative competence in the real world. 


\subsection{Cons}

Despite the many benefits of using SNS in the classroom, there is also a lot of resistance to using it, and with good reason. There are some drawbacks and even dangers to using SNS and more specifically Facebook Live in the classroom.

One of the first major drawbacks to using SNS and Facebook Live in the classroom is technology. Many schools are not equipped with the technology to use it in the classroom and it may be unfair to students who do not have the technological devices to use it outside of the classroom. Although this may be a major obstacle in some schools, it was not one where this study was conducted. All classrooms had computers with fast internet connections and overhead projectors. Additionally, the school offers free Wi-Fi and all students had their own smartphones and Facebook accounts.

Another concern among teachers is that they are time consuming for the teacher. Moran, Seaman, and Tinti-Kane (2011) reported that "a near majority of faculty report that social networks take more time than they are worth, with a large portion neutral (p. 14)." Many teachers are concerned that the time spent to manage SNSs are not worth the results. In regard to using Facebook Live, one could argue that a teacher must be able to coordinate or find an event that will take place during class time and contain the appropriate language and content.

Regarding its effectiveness in instruction, a significant drawback to using SNSs and Facebook Live in the classroom is that they can be a distraction in the classroom. Lederer (2012) reported, "a common complaint among educators is that social media is distracting in the classroom. These instructors maintain that tools like Facebook and Twitter divert students' attention away from what's happening in class and are ultimately disruptive to the learning process. (p. 2)."

A range of potentially more serious concerns can arise with using SNSs in the classroom. Many teachers are worried that they will be misused in the class and detract from student output and achievement, and are also concerned about privacy and the content. These are valid concerns that must be addressed. Moran et al. (2011) stated that "the two most important concerns are privacy and integrity: $80 \%$ report that 'lack of integrity of student submissions' is an 'important' or 'very important' barrier, and over $70 \%$ say privacy concerns are an 'important' or 'very important' barrier (p.16)." In addition to privacy and integrity, teachers must also be aware of the content. Specifically, with Facebook Live, it is important that students only use videos from trusted sources that will use appropriate language and talk about appropriate content. Boghian (2013) argued that since it becomes part of the classroom, using Facebook requires "compliance with a certain moral and ethical etiquette (p. 93)." Therefore, it is very important for teachers to make sure that the content shows compliance to the standards of the classroom and school.

Despite the reported benefits of using SNSs in the classroom, teachers must be aware that there are many potential drawbacks which can impact the effectiveness of instruction and the output and performance of learners, and these must be weighed against the potential benefits outlined above.

\section{Methodology \\ 3.1. Research Question}

Does Facebook Live offer students a more authentic and engaging listening experience compared to traditional CD listening activities?

\subsection{Context and Participants}

The purpose of this study was a follow up to a previous study that was designed to see if Facebook Live could be used effectively in a Korean university EFL curriculum. In this study, 24 participants ranging from 18-21 were chosen as a convenient sampling and were divided into three groups of 8. All 24 spoke Korean as their L1 (first language) and English as their L2 (second language).

The participants were divided into three groups, and each group of 8 received a different treatment of the same listening content: a CD recording, an interactive Facebook Live session, and a replay of a Facebook Live session. The first group listened to a CD recording, which is a very typical listening activity in many EFL classrooms. The second group watched a Facebook Live stream on the same content on their individual smart phones and were encouraged to interact with the speaker by typing in questions or comments. The third group watched a replay of the Facebook Live stream via an overhead projector and weren't able to interact with the speaker. The duration of the CD recordings and Facebook Live sessions were identical. After listening or watching, the students completed a survey.

All participants already had the Facebook app on their smartphones and most had previous experiences with Facebook Live. The Facebook Live event was a coordinated in advance and was scheduled to occur at a specific time. The participants were encouraged to interact with the presenter by typing comments or questions on the content of the discussion during the course of the broadcast, and the presenter was instructed to end the Facebook Live event after a certain time to keep both recordings the same length. The third group watched a replay of the Facebook Live session via an overhead projector and focused on listening, because they couldn't interact with the speaker. Each group did a post listening questions and engaged in a discussion in order to gauge comprehension. 
After each group finished their respective activity, they were asked to complete a survey. The survey contained eight questions based on a 5 point Likert scale, with 1 being strongly disagree, and 5 being strongly agree, and a comment section and was designed to gauge student feedback on each medium. Questions were designed to see which activities students felt were more interactive, engaging, authentic, and helpful. In addition to the survey, three students from each group were interviewed individually in an attempt to elicit more feedback and suggestions. During the interviews, students were asked to go more in-depth about the pros and cons and encouraged to discuss how they felt about the activity.

After completing both listening activities, the questionnaires were collected. The three participants from each group were each then interviewed separately. All of the questionnaires were completed and the notes from the interviews and questionnaires were analyzed to see if there was a preference for one of the activities and to see why evaluate the pros and cons of each activity. During the interviews, students were asked to go into more depth about the pros and cons of each activity.

\section{Results and Analysis}

The overall feedback for the Facebook Live activities was significantly more favorable than the CD listening activity; students found the Facebook Live activities to be more interactive, engaging, and authentic. The qualitative feedback that was given during the interviews highlighted why the Facebook Live activities scored higher and why the CD activity received lower scores. The strengths for the listening activity was that it was something that they were used to doing and that it is a format that they often experience in testing. The most common weakness about the CD listening activity was that it was difficult to picture the setting and the activity that was going on. Participants also responded that this type of activity needs more background information to be given before the listening activity started.

The feedback for the Facebook Live activities was much higher across the board. The following numbers given are based on a 5 point Likert scale, with 1 being strongly disagree, and 5 being strongly agree. When asked if they found the listening activity interactive, the CD activity scored 1.75, The Facebook Live with interaction scored 4.875 and the Facebook Live without interaction scored 3.75. Not surprising, similar results were found for the question that asked if the activity was engaging. The CD activity scored 2.5, The interactive Facebook Live activity scored 5, and the Facebook Live activity without interaction scored 4.125. When asked if the found the activity to be boring The CD activity received a score of 4.375 , while both Facebook Live activities received scores of 1.125. In terms of the weather or not visual element was beneficial, the $\mathrm{CD}$ activity scored 1.5 on a question that asked if the lack of a visual elements was helpful. This number was a stark contrast to the Facebook Live numbers on the question that asked if the visual element was beneficial. The one with interaction scored 4.125 and the one without interaction scored 4.625 .

The interviews backed up these numbers, as students noted that lack of interaction and engagement in the $\mathrm{CD}$ activity which contrasted the feeling of the groups that watched the Facebook Live activities. In contrast to the CD listening activity, one of the strengths given for the Facebook Live activity was that the content and context were easily understood. While students in the group that listened to the CD commented about being lost and confused at the start, those in the Facebook Live groups praised the visual element of the activity. They felt that by seeing the setting and the speaker that they were better able to understand the situation and focus immediately. These comments weren't surprising. Burt (1999) argued that "Videos are a powerful tool in helping English language learners improve their language skills. They provide the learner with content, context, and language." All three activities provided the participants with language, but participant feedback showed that the Facebook Live activities offered a better understanding of the content and the context.

While the Facebook Live activities scored much higher on most questions, there was one question that showed a possible drawback to the interactive element of Facebook Live. When asked if they found the activity to complicated, the students gave the Facebook Live activity a score of 4.875 compared to scores of 1.875 for the Facebook Live activity without interaction and 1.75 for the CD activity. The interviews highlighted this concern as the students from the interactive Facebook Live activity commented on the difficulty of multitasking during while listening. One student said, "it was too hard to listen, type, and watch. I liked it, but my question wasn't good."

Another strength of Facebook Live was that it was viewed as more authentic. The interactive Facebook Live activity scored 4.625 and the Facebook Live activity without interaction scored 4.875 on the question that asked if it was authentic. The CD activity only scored a 1.75 on this question. The qualitative data from the interviews really highlighted that the students viewed the CDs as academic resources and not authentic materials. When one student asked about who they thought was speaking and why they were speaking, the student said, "some actor, in some studio somewhere. I don't remember where they said they were supposed to be, but I don't think they were there." This was really different from the comments about the Facebook Live activities. The students from both Facebook Live groups really enjoyed seeing and listening to a person in another country. This is especially encouraging, because it is a way that may allow ELT teachers to expose students to a variety of different English speakers from all over the world.

One of the primary purposes and perceived benefits of introducing Facebook Live to students was that it 
was something that students may access outside of class. Because most language classes have a finite amount of class hours, giving students activities that they will enjoy and use outside of class is something that cannot be underestimated. On the question that asked if students would consider using the activity outside of classroom the $\mathrm{CD}$ activity was rated at 2, while both Facebook Live activities were rated at 3.5. During the interviews, it became clearer that many students were already watching and listening to Facebook Live or other streams on social media in English naturally and would sometimes even interact with them. Most students hadn't thought about the language benefit of these interactions, and merely viewed them as ways to find out more about their interests.

\section{Discussion and Recommendations}

The quantitative and qualitative data collected shows that Facebook Live is perceived as engaging, interesting, and authentic. While there may be some drawbacks to using Facebook Live in the EFL classroom, the benefits should encourage EFL teachers to find ways to integrate Facebook Live listening activities into their course design.

While the Facebook Live with interaction scored higher in a few categories, it might not be the ideal way to use Facebook Live in a listening activity. One of the biggest drawbacks would be that it would require all students to use their own phones in the class, which could present many obstacles. If teachers do choose to go this, they should make sure all students have a smart phone and access to free Wi-Fi. In addition, the students seemed to be slightly overwhelmed by having to listen, watch, and respond. This concern might be addressed by having the class work up to this level of interaction gradually, rather than having them do everything at once. Teachers can use Facebook Live only for listening and eventually work up to having the students listen and respond in various ways as the semester progresses.

Another clear benefit is that Facebook Live offers teachers a way to expose students to a variety of English speakers and this exposure might help the students to broaden their perspectives about English in a global context. This is especially important, because many ELT resources fail to expose students to non-native speakers. Many topics found in popular ELT books are universal and speakers from around the world can share their opinions and insights on these topics via Facebook Live.

One final benefit that wasn't discussed in this limited study is that Facebook Live offers teachers a chance to expose their students to not only a variety of topics, but also various formats. Facebook Live broadcasts can be anything from a simple discussion to even a lecture given by a professional. Additionally, because the Facebook Live is broadcasted live, students are getting update to date information and perspectives, which isn't always the case with $\mathrm{CD}$ activities.

\section{Limitations}

This study was done at one location using a very small group of participants. Also, the study dealt with how students perceived the activities and didn't exam the effectiveness of each activity. Although the study was small and based mainly on student opinions, the findings showed that Facebook Live warranted future use in the classroom.

It is important to note that most of the cons listed in the Literature Review are valid objections to using Facebook Live in the classroom. Teachers must make sure that the classrooms are equipped with the proper technology and they must make sure that the sources that they use are both reliable and ethical. If teachers decide to use Facebook Live in the classroom, they should make sure it is a coordinated event and not a random broadcast that might be off topic, or contain inappropriate content or language.

\section{Conclusion}

Although the sample size was small and the research focused only on participant feedback and not on performance, there was enough positive feedback to warrant additional use in the classroom. Although there are many apps and sites that allow teachers and students ways to listen to and watch various people outside of the walls of the classroom, the popularity and ubiquitous nature of Facebook give Facebook Live an advantage over lesser used programs. Most students will already have some familiarity with Facebook and Facebook Live and may be more comfortable using them. The interviews showed that many students were already using Facebook live outside of the classroom although they weren't thinking about it as a language learning task.

In addition, Facebook's popularity makes it easier to connect with reliable volunteers willing to broadcast about topics from various locations around the world. Experts on various subjects and topics can offer students authentic listening experiences with very little time commitment. While CDs and DVDs also offer students opportunities to listen about topics, they don't provide any interaction and they are often outdated. Facebook Live allows for interaction and it is presented in real time, so the information is always current and relevant.

Although there are privacy and integrity concerns about using Facebook Live in the classroom, teachers should see this as an opportunity to help their students navigate the real world, rather than using it as an excuse to not use available technology in the classroom. Teachers should definitely make sure that they don't use any random broadcast, but rather talk to a trusted source and prepare a broadcast that can help the 
students both linguistically and academically.

As the world changes, shouldn't the way EFL teachers approach listening activities also change? Traditional audio recording offer students a chance to listen, but Facebook Live allows students a chance to interact and learn about topics and people from all over the world. This better prepares students for the global environment that they will face once they leave university.

Prensky (2005) claimed, "if educators want to have relevance in this century, it is crucial that we find ways to engage students in school (p. 9)." Facebook Live offers educators a chance to engage EFL students with a listening activity and allows the students the unique opportunity to engage with people from all over the world about any topic imaginable.

\section{Acknowledgment}

This work was supported by Hanguk University of Foreign Studies Research Fund of 2018.

\section{References}

Barseghian, T. (2011). 50 reasons to invite Facebook into your classroom. Mind shift: How we will learn. Retrieved from https://ww2.kqed.org/mindshift/2011/08/05/50-reasons-to-invite-facebook-into-your-classroom/.

Boghian, I. (2013). Using Facebook in teaching. In social media in higher education: Teaching in Web 2.0 (pp. 86-103). Hershey: PA, USA. IGI Global.

Galloway, N., \& Rose, H. (2017). Incorporating global Englishes into the ELT classroom. ELT Journal, 72(1), 3-14.

Greenberg, A. D., \& Zanetis, J. (2012). The impact of broadcast and streaming video in education. Cisco: Wainhouse Research.

Inayati, N. (2013). Systemic analysis of TESOL practitioners' use of social media in the higher education sector. International Journal of Innovation in English Language Teaching and Research, 2(2), 193-207.

Lederer, K. (2012). Pros and cons of social media in the classroom. Campus Technology, 25(5), 1-2.

Moran, M., Seaman, J., \& Tinti-Kane, H. (2011). Teaching, learning, and sharing: How today's higher education faculty use social media (pp. 14). Babson Park: MA, USA: Babson Survey Research Group.

Pegrum. (2000). Mark A. Challenging modernity: Dada between modern and postmodern: Berghahn Books.

Prensky, M. (2005). Listen to the natives. Educational Leadership, 63(4), 8-13.

Ur, P. (1984). Teaching listening comprehension. Cambridge. England: Cambridge University Press.

Wu, S. (2016). A study on the English teaching model in the Facebook environment. Theory and Practice in Language Studies, 6(9), 1791-1796.

\section{Appendix}

Chart-1. Student responses based on a 5 point Likert scale, with 1 being strongly disagree, and 5 being strongly agree.

\begin{tabular}{l|l|l|l}
\hline $\begin{array}{l}\text { Questions } \\
\text { The listening activity... }\end{array}$ & CD & Interactive Facebook Live & $\begin{array}{l}\text { Facebook Live without } \\
\text { Interaction }\end{array}$ \\
\hline was interactive & 1.75 & $\underline{4.875}$ & 3.75 \\
\hline was engaging & 2.5 & $\underline{5}$ & 4.125 \\
\hline was boring & 4.375 & $\underline{1.125}$ & $\underline{1.125}$ \\
\hline was authentic & 1.75 & 4.625 & $\underline{4.875}$ \\
\hline was helpful & 3.75 & 4.125 & $\underline{4.625}$ \\
\hline was complicated & $\underline{1.75}$ & 4.875 & 1.875 \\
\hline $\begin{array}{l}\text { I would consider using it outside of the } \\
\text { classroom }\end{array}$ & 2 & $\underline{3.5}$ & $\underline{3.5}$ \\
\hline $\begin{array}{l}\text { The visual aspect or lack of a visual } \\
\text { aspect was beneficial }\end{array}$ & 1.5 & 4.125 & $\underline{4.625}$ \\
\hline
\end{tabular}

